Página inicial: 427 - Página final: 452

Tipo de artículo: de investigación

\title{
Apoyo mutuo, liderazgo afectivo y experiencia clínica comunitaria. Acompañamiento psicosocial para la "rehabilitación" de víctimas del conflicto armado.
}

\author{
Mutual support, affective leadership, and community clinic \\ An experience of psychosocial accompaniment for the "rehabilitation" of victims of the armed conflict.
}

Recibido: enero 2016 Revisado: abril 2016 Aceptado: mayo 2016

Por: Juan David Villa Gómez ${ }^{1}$, Nadis Milena Londoño ${ }^{2}$,

Marcela Gallego, Laura Isabel Arango ${ }^{3}$, Michelle Rosso Pérez 4

\begin{abstract}
Resumen.
Se presenta la sistematización de una experiencia de acompañamiento psicosocial a víctimas del conflicto armado en la ciudad de Medellín. Este estudio, permitió comprender y evidenciar que las estrategias de fortalecimiento comunitario, la formación de líderes y lideresas afectivos/as, el apoyo entre iguales, la acción psicosocial desde la potenciación de las comunidades y sus redes de apoyo, son acciones pertinentes para generar empoderamiento personal y colectivo, recuperación emocional, transformaciones subjetivas y experiencias de reconstrucción de proyectos de vida, del tejido social y redignificación de víctimas del conflicto armado en Colombia. Se propone así, desarrollar procesos de reparación integral desde las comunidades más que ejecutar, desde arriba y de forma vertical, proyectos por lo general, alejados de las necesidades y posibilidades de la gente.
\end{abstract}

\section{Palabras claves.}

Psicosocial, Reparación, Rehabilitación, Apoyo Social, Víctimas.

\begin{abstract}
.
The systematization of an experience of psychosocial accompaniment to victims of the armed conflict in the city of Medellin is introduced. This study allowed to understand and to demonstrate that the strategies for community strengthening, the training of leaders and affective men and women leaders, the peer support, the psychosocial action from the empowerment of communities and their support networks, are necessary actions to generate personal and collective empowerment, emotional recovery, subjective transformations, and experiences of reconstruction of projects of life, the social fabric, and the re-dignification of victims of the armed conflict in Colombia. It is therefore proposed to develop processes of integral repair from the communities rather than to carry out, from above and vertically, projects, usually away from the needs and possibilities of the people.
\end{abstract}

\section{Key words.}

Psychosocial, Repair, Rehabilitation, Social Support, Victims.

\footnotetext{
${ }^{1}$ Psicólogo, Pontificia Universidad Javeriana (Bogotá - Colombia). Magister y PHD, Cooperación Internacional al Desarrollo Universidad Pontificia de Comillas (Madrid - España). Docente / Investigador Facultad de Psicología Universidad San Buenaventura (Medellín - Colombia). Contacto: juand.villa@usbmed.edu.co

${ }^{2}$ Psicóloga Universidad de San Buenaventura Medellín, promotora proyecto líderes y lideresas efectivas, personal para la atención psicosocial a víctimas de violencia política. Medellín (Colombia). Contacto:

${ }^{3}$ Psicóloga Universidad de San Buenaventura Medellín, promotora proyecto líderes y lideresas efectivas, personal para la atención psicosocial a víctimas de violencia política. Medellín (Colombia). Contacto:

${ }^{4}$ Psicóloga Universidad de San Buenaventura Medellín, promotora proyecto líderes y lideresas efectivas, personal para la atención psicosocial a víctimas de violencia política. Medellín (Colombia). Contacto:
} 
MUTUAL SUPPORT, AFFECTIVE LEADERSHIP, AND COMMUNITY REHABILITATION.

ANEXPERIENCE OF PSYCHOSOCIALACCOMPANIMENT FORTHE "REHABILITATION" OFVICTIMSOFTHEARMED CONFLICT.

\section{Introducción.}

El presente artículo surge como producto de la sistematización investigativa de un proceso formativo a "Personal para la atención psicosocial a víctimas de violencia política", desarrollado por la Universidad San Buenaventura, la Alcaldía de Medellín y la OIM, en el que se formaron, durante año y medio, 80 personas como promotores/as psicosociales para el acompañamiento a víctimas del conflicto armado en la ciudad de Medellín. Este proceso permitió el acompañamiento a cerca de 800 personas víctimas de violencia política, a través de la metodología de los grupos de apoyo mutuo (GAM), en los cuales cada líder o lideresa participante desarrolló un proceso de acompañamiento psicosocial por 15 sesiones durante un año.

Este proyecto estuvo relacionado con otras propuestas desarrolladas en algunas regiones del país, como las promotoras de vida y salud mental (PROVISAME), realizada por al Programa por la Paz / CINEP, Conciudadanía y la Asociación de Mujeres del Oriente Antioqueño (AMOR), además de los procesos de formación de terapeutas y multiplicadores psicosociales, por parte de la Corporación AVRE, entre otros. El objetivo se centraba en realizar procesos de apoyo mutuo en las comunidades y abrir espacios alternativos para la rehabilitación psicosocial en un contexto de aplicación de la ley 1448 de 2011 (ley de víctimas) como un aporte a la reparación integral, en un modelo que recoge las capacidades y potencialidades de las comunidades y sus líderes y lideresas afectivos/as para reconstruir proyectos de vida, tejido social, recuperar la dignidad de las víctimas y su dimensión emocional.

\section{Metodología.}

La investigación realizada, buscaba evidencia sobre el impacto generado por el proceso de acompañamiento psicosocial desarrollado por los/las Promotores/as psicosociales, para fundamentar la importancia de este tipo de procesos para la reparación de las víctimas en la medida de rehabilitación. Se desarrolló una investigación cualitativa a través de grupos focales con los líderes y lideresas que asistieron al diplomado y con las personas que participaron de los grupos de apoyo mutuo que dichos líderes acompañaron en el proceso de réplica de la experiencia. En total se desarrollaron 15 grupos focales, con la participación de un total de 225 participantes.

El proceso se siguió con la grabación y transcripción de los grupos. Los textos fueron organizados e interpretados según un proceso hermenéutico de análisis del discurso: en primer lugar, a través de matrices de coherencia que permitieron un primer nivel de análisis intratextual, donde cada texto se organiza según categorías construidas. Las categorías que desarrollamos en el presente artículo son: transformaciones subjetivas (que da cuenta de los cambios individuales, familiares, comunitarios, vividos por los y las participantes en el proyecto), y reflexión teórico-metodológica, que tiene que ver con el análisis de las estrategias utilizadas en relación y discusión con las propuestas de intervención psicológica tradicionales, con el objetivo de mostrar las fortalezas y virtudes del proceso como mediación fundamental para adelantar la reparación integral en Colombia.

Las matrices de coherencia, fueron contrastados en los análisis intertextuales, que posibilitó un primer paso en la interpretación de los relatos en relación con cada categoría, ubicando los elementos comunes y diferenciales en los/as participantes; para luego producir un segundo momento de interpretación siguiendo un proceso de codificación teórica de primer y segundo nivel (Villa, 2014; (Flick, 2004). De allí derivó texto completo que a continuación se presenta, el cual es un tejido en el que emergen las voces del equipo investigador que realiza el proceso interpretativo de los relatos y narrativas recogidas, que 
aparecen referenciados permanentemente como parte del análisis. Finalmente, este tejido se contrasta con aportes teóricos e investigativos que se han realizado con anterioridad en el marco de la intervención psicosocial en otros contextos y latitudes, invocando a algunos autores que tienen un reconocimiento académico en el tema y contrastando con teorías y procesos conceptuales que puedan dialogar con nuestro proceso de interpretación.

\section{Resultados.}

\section{Transformaciones subjetivas.}

Cuando hablamos de acompañamiento psicosocial estamos refiriendo un proceso que se dirige a favorecer las interacciones humanas y los contextos en los cuales participan los sujetos, mediante la transformación o tratamiento del mundo emocional; pues en los vínculos se expresa la calidad del universo interno del sujeto, afectando de manera directa la calidad de las interacciones y estas, a su vez, en la emocionalidad (González Rey, 2011). Por ello vemos relevante poder dar cuenta de la manera en que el mundo subjetivo de los/ as participantes se transformó tras el proceso vivido, pues los cambios positivos en esta dimensión, siempre serán una promesa de bienestar para el sujeto y el mundo que le rodea.

En los grupos focales, aparece con bastante relevancia la referencia al acompañamiento como oportunidad para desahogarse, para soltar las penas o historias dolorosas que los/as mantenían oprimidos/as. Esto es lo que en psicología se puede definir con el concepto de catarsis, que indica liberación de emociones, descarga afectiva del exceso de afecto puesto en una experiencia, generando sensación de libertad y bienestar. De manera similar, en los procesos realizados en el Oriente Antioqueño y sur de Córdoba, los participantes manifestaron que su primera forma de transformación se dio cuando tuvieron la vivencia catártica (Villa, 2014a).

Tanto los/as promotores/as como las personas que ellos/as acompañaban cargaban historias que no habían sido nombradas ni expresadas, acumuladas en sus recuerdos con toda la emoción, a causa del miedo, el aislamiento o porque no habían encontrado oídos para ser escuchadas y validadas. Por tanto, para los/as participantes este proceso fue una oportunidad para desahogarse, para decir aquello que no había podido salir y que era causa de malestar y sufrimiento, tanto porque el dolor oprime y no permite que emerja, como por el miedo a sufrir nuevas formas de violencia, es decir, se pudo nombrar lo innombrable (Villa Gómez, Tejada, Sánchez, \& Téllez, 2007):

Me sirvió, en primer lugar, porque me permitió sacar cosas que estaban por allá guardadas y que estaban haciendo daño, entonces para mí esto ha sido bendición y satisfacción a la vez (GF2). Aprendí a decir lo que sentía, lo que me ahogaba con dolor, las cosas que uno va guardando... pues que uno ya no es un niño un adolescente, entonces tiene demasiadas cosas que lo ahogan, que muchas veces no ha dicho por temor, porque nunca lo escucharon, pero uno tampoco buscó la forma de soltarlo, de buscar hablar, y para mí el cambio ha sido muy grande en mi familia y en mi comunidad. (GF5)

Si bien la catarsis posibilita la recuperación emocional, por su efecto terapéutico de alivio sobre la tensión emocional, no es suficiente para generar transformaciones subjetivas, ya que no implica necesariamente la resignificación de lo vivido. En este sentido, en el proceso de acompañamiento, muchas personas indican que además de descargar recuerdos dolorosos, lograron resignificar experiencias, al poner en común y contrastar sus historias con otras vivencias, muchas veces, más difíciles que la propia; por tanto, revaloraron su propia experiencia, modulando la emoción y resignificando el sufrimiento. Operaba un 
MUTUAL SUPPORT, AFFECTIVE LEADERSHIP, AND COMMUNITY REHABILITATION.

AN EXPERIENCE OF PSYCHOSOCIALACCOMPANIMENT FORTHE "REHABILITATION" OFVICTIMSOFTHEARMEDCONFLICT.

proceso de identificación con la experiencia del otro, frente a la cual se puede referenciar la propia, dándole nuevos sentidos y experimentando que, al compartirse el dolor, éste se hace más llevadero; además, porque en el ejercicio de la escucha emerge la necesidad de apoyar a los otros/as, de tal manera que se construye el apoyo mutuo que permite resignificar el propio dolor (Villa, 2014a):

...Yo he cambiado primero la desconfianza, porque si nosotros no dejáramos eso, no estaríamos acá, esto es algo que ayuda mucho sicológicamente, yo escucho a las demás personas y pienso en lo que me ha pasado y me doy cuenta que no soy la más afectada, hay personas a las que les ha pasado cosas peores de las que me han pasado a mi (GF7).

En este proceso el dolor personal se transforma en dolor compartido, dolor social, lo que fortalece los lazos, facilitando el alivio, la recuperación emocional y la reconstrucción de confianza (Villa Gómez J. D., 2013a); (Villa, et. Al, 2007). Para avanzar en la re-significación de la experiencia, fue necesario también que los participantes pudieran empezar a salir de su "postración" (Villa Gómez J. D., 2013a); (Villa Gómez J. D., 2014b) ; (Villa Gómez J. D., 2016) ; lo que implica una postura corporal diferente, más erguida, con la mirada al frente y con proyección posible, pudiendo volver a conectar con sus sueños, verse de manera diferente y emprender nuevos proyectos: Para mí haber participado en este proceso, ha sido recuperar fuerzas, recuperar mi vida, salir de la postración, hallarle sentido a la vida, entender que vale la pena vivir... porque no solamente nos estamos ayudando a nosotros, sino también a otras personas (GF2). Así, las personas recuperan su dignidad, reconocen su propio valor, se desculpabilizan y reconquistan su propio merecimiento, sin que la historia de victimización defina toda su experiencia vital. Por tanto, expresiones como: "volver a nacer", "ser otra persona", "transformarse", evidencian que el acompañamiento posibilita la transformación de experiencias vitales de desvalimiento, indefensión, sumisión y dependencia.

...Me siento fortalecida, uno se puede levantar de la nada y dar brote a tantas cualidades escondidas, uno puede ser ejemplo para otras mujeres... (GF2). Yo aquí gané fuerza, pero no fuerza física...Yo gané fuerza emocional, que se expresa desde adentro. Fuerza como para poder decidir, como persona, como mujer. Para tomar otra vez mis sueños y empezar otra vez a luchar por ellos (GF3).

...este proceso fue la oportunidad de volver a vivir, lo he repetido mucho y lo seguiré haciendo hasta que haga eco: yo respiraba, pero no vivía. Aquí me han enseñado a valorarme... a sentir el dolor ajeno, a saber recibir, porque era muy duro entender que gente buena sí hay; llegué a pensar que todo el mundo era malo, encerrarme casi 11 años, a hablar sólo con mis hijos por físico miedo o por creer que todo el mundo era malo (GF1).

Este paso de conexión con la vida se relaciona con la elaboración de duelos que refieren los/ as participantes; puesto que contar la historia, tener memoria de los hechos y comunicarla, en espacios grupales y/o terapéuticos, desde varios escenarios y visiones de la psicología ha sido considerado como algo positivo: en el psicoanálisis, desde Duelo y Melancolía (Freud ,1915/1917) reafirmado por Kaufman (2006), entre otros. En los modelos del TEPT con el Debriefing y las terapias narrativas (Pennebaker J. , 1994); (Pennebaker \& Crow, 2000) (Pillemer, 2003) y desde una perspectiva más psicosocial, los marcos terapéuticos testimoniales (Aron, 1992) ; (Lira, 2011) ; (Lira \& Castillo, 1993). En este proceso de elaboración de duelo, las personas realizan varias tareas: expresar, aceptar, adaptarse y reconstruir la propia identidad, recordar y restituir vínculos con los seres queridos que 
se han ido (Martin Beristain, 1999). Tareas que se posibilitaron en los GAM a través de un trabajo profundo, que implicó la apertura a otros/as, la reconstrucción de vínculos y relaciones y la aceptación de la vida y de nuevas experiencias:

...todos vinimos con un dolor personal, con una pérdida, con una inquietud y la posibilidad que se nos dio de socializarlo, de compartirlo nos ha dado oportunidades de entender y comprender que podemos seguir adelante... Nos han transformado a ser otras personas, y cuando vinimos acá muchas no hablábamos, o estábamos aquí y no sabíamos el por qué, porque teníamos un dolor de ese ser querido que ya no está, pero aquí nos han enseñado a caminar, a dar pasos gigantes de saber llevar ese dolor y convivir con él (GF4).

Emergió entonces la recuperación de sentidos vitales. Las personas retoman proyectos personales y sueños que habían sido postergados, negados o desatendidos por los duelos vividos o por otras situaciones vitales de sufrimiento que se lograron resignificar tras el apoyo mutuo; por lo que sienten que este proceso salvó sus vidas permitiéndoles abrazarla y celebrarla de nuevo, conectándose además con la esperanza de un futuro diferente y con las ganas de ponerse en acción:

... Yo digo que si hay cielo es esto acá, porque prácticamente donde no existiera, yo digo que yo estaría muerta porque yo tenía una depresión horrible... Y me sentía como... a mí me parecía que la gente me miraba, que se burlaban de mí... pero yo ahora ya... imagínese tanto he botado la sicosis o no sé qué... porque prácticamente ahora ya me mantengo aquí y estudio; imagínese que antes tenía oportunidades de estudiar y no estudiaba; mejor dicho tengo mucho que agradecerle a E. porque si no fuera por esto, por Dios lindo que yo estuviera muerta, mejor dicho fue una mano grandísima para mí... (GF14)

Así pues, este tipo de procesos permite que las personas reconozcan su capacidad resiliente, para afrontar la adversidad y recuperarse luego de una situación difícil: "Sirve bastante para empoderarnos de nuestra situación, de nuestro entorno y tratar al máximo de cambiar el papel de víctimas... el protagonista de mi vida soy yo, y soy yo quien puedo ir escribiendo cada día de la mejor manera, esa forma de vivir..." (GF10).

Otro elemento fue la tramitación de la rabia, el odio y el resentimiento. De acuerdo con Villa (Villa Gómez J. D., 2013a) la rabia hace parte del repertorio emocional con el cual una víctima enfrenta o simboliza la experiencia vivida, esta emoción se instala de manera especial por las condiciones de los hechos vividos: la crueldad con que estos ocurrieron, la sevicia de los perpetradores, la ausencia de justicia, etc. Además, cuando estas emociones no han tenido espacios de expresión se asientan y se enquistan haciendo que la rabia se convierta en odio y con ello se alimenten deseos de venganza:

Antes llegué con un peso encima, una carga que no podía con ella, me sentí llena de odio, triste y confundida, dibujé una muñequita con lagrimitas, triste; después, aprendí a quererme a mí misma, a perdonar, a sacar el rencor, el odio y soy feliz, escogí este color verde, porque significa esperanza para mí (GF15).

Culturalmente la rabia ha sido una emoción deslegitimada, especialmente para las mujeres; por esta razón suele reprimirse, con lo cual toda esta energía queda atrapada en el sujeto, generando enfermedades psicosomáticas o haciendo que la agresión se redirija contra sí mismo o contra la familia. El apoyo mutuo ha permitido, por tanto, que los/as participantes retomen un nivel de control sobre su propia existencia (Lira, 2011): el mundo 
MUTUAL SUPPORT, AFFECTIVE LEADERSHIP, AND COMMUNITY REHABILITATION.

AN EXPERIENCE OF PSYCHOSOCIALACCOMPANIMENT FORTHE "REHABILITATION" OFVICTIMSOFTHEARMEDCONFLICT.

de la vida vuelve a estar enmarcado dentro de esquemas cercanos y comprensibles, se abren posibilidades para retomar relaciones y actuar sobre la realidad personal, potenciando que se pudieran mirar a sí mismos/as de manera crítica en la construcción de las relaciones y su ética: ...Crecí en controlar las emociones, en entender al otro, en no creer que a toda hora uno tiene la razón, que también los demás la tienen; en ponerme en los zapatos de los demás, aprender a saber escuchar, entender...(GF3).

Así pues, este proceso permite la transformación de sentimientos de odio y la canalización de la rabia, con un posicionamiento diferente frente a la imagen o idea del agresor. En términos psicosociales, estos cambios subjetivos pueden contribuir a un clima colectivo de pazy reconciliación, que afronte los discursos sociales que intentan ahondar en la venganza, la violencia y la guerra, los cuales suelen implantarse en la subjetividad, razón por la cual deben ser revertidos (Bar-Tal, 2000) (Bar-Tal, 2003). Por lo tanto, el apoyo mutuo posibilita llegar a las emociones profundas de los/as participantes y desactivar representaciones, sentimientos y relatos que son utilizados sistemáticamente para perpetuar la guerra, mediante la acción de nombrar lo innombrable (Villa, et. al, 2007), la expresión y acogida de relatos de dolor, rabia y frustración, el apoyo, la contención y la solidaridad (Villa, 2013a):

Por ejemplo, yo me encontraba con las personas que nos hicieron daño, yo sentía mucha rabia, no las quería ni ver y me encontré con unas y fui capaz de mirarlos... fui capaz, porque yo los veía y yo los quería era como matar, yo les expresaba como rabia y ya fui capaz de pasar y pasé por un lado normal, como si fuera cualquier otra persona (GF5).

Este proceso personal no implica renunciar a la verdad, a la justicia o a la reparación, cuya aplicación se dirime en una negociación de orden político; sino que implica una dinámica personal y colectiva de sanación, bienestar, recuperación de fuerza, reconstrucción de confianza y autoafirmación (Villa, 2016b). Se trata de una sanación emocional gracias a la escucha, la solidaridad y la horizontalidad, es decir, al ejercicio de razón compasiva y transformación desde abajo como praxis básica de la psicología de la liberación (Blanco \& Gaborit, 2007). Para los/as participantes, el espacio grupal de contención y apoyo, rompe entonces con el aislamiento, el silencio y la "prohibición" implícita que experimentan en sus familias para hablar de lo vivido

...antes de venir a éste grupo yo me sentía muy sola y encerrada, me mantenía en la casa viendo televisión, eso no es bueno. Por una parte, como tristeza, y con estos grupos me siento mucho mejor, más integrada, he conocido muchas amistades y me parece muy bueno para la salud, para uno no estar solo y salir de la tristeza y no mantener encerrada (GF13).

Por último, vale la pena resaltar que esta manera de acompañar tiene efectos terapéuticos, que se evidencian no sólo en el reporte de una mejoría anímica, sino también en la mejoría de pronóstico de algunos diagnósticos psiquiátricos, adicciones y procesos terapéuticos con los que llegaron algunos/as participantes; además, en la posibilidad de algunos/as de abandonar la medicación psiquiátrica, manteniendo un equilibrio emocional aportado por una mejoría en la salud mental. En el Oriente Antioqueño y en el sur de Córdoba, también se presentaron varios casos en los cuales el apoyo mutuo, la solidaridad, el encuentro, el contacto personal, el abrazo y la confianza, permitieron superar la medicalización; lo que pone de manifiesto la fuerza de lo relacional y del lazo social en la recuperación emocional (Villa Gómez J. D., 2013a), (Villa Gómez J. D., 2013b), (Villa Gómez J. D., 2014a): 
Antes de llegar al proceso yo me mantenía por allá sentadita en el sol, yo estuve enferma, hospitalizada. Me mandaron Fluoxetina, Diazepam, Acetaminofén que es lo que mandan, para relajarme, porque sufría depresión de todo lo que me ha pasado; en la que me daba mucha tristeza y uno no quiere hablar con nadie, ni salir con nadie, me daba mucho frio y mucha comedera, me daba ansiedad; el que tiene frio se acuesta y el que tiene ansiedad come... Yo hacía las dos cosas, pero ninguna de las dos es suficiente... entonces estuve hospitalizada y me mandaron esa droga y eso más me abobada. Entonces ya dejé esa droga y me siento como mejor, muy animada, volví a danzas, eché de ver que tenía mi jardín enrastrojado; ya cogí a desherbar mi jardincito, le hecho agüita... el oficio siempre se lo dejaba a las muchachas cuando llegaran de estudiar; pero ya me animo y arreglo casa, barro, trapeo, y acá me he sentido muy bien: porque todas me conocen, pasamos a conformar, a ser una familia... estoy animada gracias al grupo (GF14).

Hamber (2008) (2011) Martín Beristain (2005), Lykes (2001a) (2001b), Fulchiron (2011), Villa et al. (2007) entre otros, sugieren que la reconstrucción y fortalecimiento del lazo social y afectivo genera transformaciones subjetivas, ya que el daño que viene de afuera, de lo social y político, es elaborado en un espacio también social, colectivo y comunitario, lo que redunda en procesos de sanación individual; por tanto, se desarrolla una experiencia clínica comunitaria (Montero, 2011), que transforma el orden social, relacional y psíquico desde una praxis sustentada en una visión ontológica del ser humano como construcción relacional y social, que se afianza o enferma en los marcos sociales que lo atraviesan:

...cuando a mí me invitaron a este espacio, yo fui traguiada, nadie se dio cuenta, yo estaba borracha. Ahí estaba Á., S. y doña L., y me recibieron muy bien. Y yo aburrida, lloraba, creo que ustedes se acuerdan, yo llegué llorando allá y fui como a dos traguiada. Y ahora, yo misma estoy extrañada porque no volví a beber... este espacio le ayuda a uno a superar, yo no volví a beber, um, um (Mueve la cabeza negativamente), para nada (GF11).

En nuestro concepto estamos ante una posibilidad real y factible de ejercicio clínico desde la psicología de orden comunitario, con posibilidades reales de transformación, evidenciadas en la presente sistematización, en autores previamente referenciados y en otras experiencias investigativas en Colombia (Villa Gómez J. D., 2013a) (Villa Gómez J. D., 2013b) (Villa Gómez J. D., 2014a); (AVRE, 2002); (Martín Beristain, 2005)

\section{Transformaciones familiares y colectivas.}

Las transformaciones individuales han repercutido a nivel familiar y colectivo. El conflicto armado suele tener consecuencias significativas en la familia, impactando en el ejercicio de autoridad, los límites, la comunicación y generando rupturas y separación. De hecho, los/as participantes reportaron que venían de vivir fuertes experiencias de violencia, desacuerdo y conflicto en sus familias; sin embargo, el acompañamiento les ha permitido tejer relaciones de solidaridad, afecto y respeto, asumir actitudes que han mejorado las relaciones y tener mayores recursos emocionales para afrontar las experiencias de manera más reflexiva:

Pues esta formación me regaló una mirada nueva o refrescante, frente a lo familiar (GF3). Yo explotaba con todo, con mi pareja, yo creía que lo estaba haciendo bien cuando en realidad también lo estaba ofendiendo de otra forma, entonces todo esto que uno va aprendido, me va diciendo que bueno pilas, usted está aprendiendo algo y para ponerlo en práctica, primeramente, en su vida, en su familia y luego en su comunidad (GF4). 
Los/as participantes comenzaron a dedicar más tiempo a la pareja e hijos y a tener actitudes más empáticas. Por tanto, en coherencia con los planteamientos de la psicología de los sistemas familiares, la transformación personal derivada de la experiencia en los GAM repercute en el entorno familiar, ya que el movimiento de una de las partes repercute en todo el sistema (Pakman, 1998), generando bucles de retroalimentación positiva hacia adentro y hacia afuera: mejoría subjetiva en lo emocional y relacional y nuevas posibilidades de actuación a nivel social y comunitario. Así pues, los cambios emocionales que se han vivido en este proyecto, transforman también imaginarios y actitudes frente a otros miembros del sistema familiar:

Me ocupaba mucho del trabajo y de otras cosas, menos de mis hijas, ellas me reclamaban, entonces yo dije: no pilas pues, entonces todo el recorrido y lo que he vivido aquí me ha enseñado muchas cosas, ya entiendo más a mi esposo, trato de repartir mi tiempo y todo lo demás (GF4). Con respecto a mi hijo grande, he tratado como de cambiarle la historia, porque él ya tiene 18 años y ha sido muy resentido; él tiene la convicción de que tiene que vengar la muerte de su papá, entonces ha sido un reto muy grande, cambiarle la historia... pero siento que he logrado mucho porque siento que su corazón se ha tocado mucho (GF1).

Por tanto, los/as participantes sienten que han trascendido relaciones de verticalidad, agresividad y violencia, para establecer en su hogar vínculos más horizontales, afectuosos y dialogantes. La horizontalidad fue una actitud en la que se insistió mucho en el proceso, para la praxis de actuación psicosocial, para la relación entre los miembros del GAM y para la reconstrucción de relaciones democráticas e incluyentes (Villa Gómez J. D., 2013b). La horizontalidad permite ser y estar con otros/as en equidad, mejorar la comunicación y recurrir al diálogo para tramitar conflictos; al tiempo que se fortalecen expresiones de afectividad para afianzar lazos y tener mayor armonía familiar:

...ha cambiado el aprendizaje en mi manera de tratar los hijos. Hace poco, tuve una reunión con los dos hijos, y yo miraba cómo usaba cosas de la formación, y es algo muy nutritivo, algo muy fuerte, este proceso es muy bueno, muy efectivo, y realmente uno ve como cada cosa que uno aprende, da unos resultados tremendos y me gusta esa parte... realmente en ese momento hubo una reforma en mi familia, pero yo apliqué mis conocimientos, cosas que he escuchado acá y realmente hubo un cambio fuerte... y fue muy efectivo (GF1). Los cambios fueron muchos, no dialogaba en la casa. Yo llegaba de hacer lo que hacía en el día, cocinaba, y no me interesaba nada, ahora me preocupo más por lo que pasa, por mi familia, por lo que sucede en la vida diaria... (GF2)

De acuerdo con Bronfrenbenner (1987) y Herrero Olaizola (2004) cualquier intervención social con perspectiva psicosocial sistémica tendrá un impacto en los diferentes niveles del sistema, mucho más cuando los dispositivos pedagógicos y metodológicos apuntan a procesos que no se quedan sólo en el sujeto individual, sino que restablecen relaciones y vínculos, tal como se anotó en el acápite anterior. Desde allí, los microsistemas familiares y los mesosistemas comunitarios, sociales e incluso políticos también experimentan movimiento y transformación en órdenes de impacto diferencial pero real (Villa, 2014a).

Adicionalmente, el proyecto permitió transformaciones en las pautas que legitimaban la violencia intrafamiliar, a través de la potenciación del afecto y del cambio de pautas de relación basadas en la agresión verbal o física, generando horizontes de buen trato y relaciones constructivas; por tanto, el ejercicio psicosocial de apoyo mutuo contribuye a prevenir la violencia intrafamiliar, en la medida en que permite dirimir mejor los conflictos: 
...descargaba mi rabia con el primero que encontrara, en especial con mis hijos, me desquitaba mucho con ellos, me cegaba la rabia y no sabía ni lo que hacía; ahora me controlo mucho, respiro y luego hablo, por lo menos los escucho frente a algo que pasa; porque antes no hablaba con ellos, sino que lo que hacía era pegarles, estoy tratando de solucionar con ellos los problemas de una mejor forma, he dejado de pegarles (GF7). Yo también he aprendido para mí y mis niñas... porque uno se cansa de hablar y trata de golpear y de insultar y yo he cambiado mucho, ya no las golpeo, ni las insulto (GF14).

Desde lo comunitario existen otras investigaciones (Fulchiron, 2011); (Villa Gómez J. D., 2014a) que logran dar cuenta de profundas transformaciones en lo colectivo porque tuvieron procesos de mayor duración que el del presente proyecto; sin embrago, a través de este último fue posible evidenciar que se logró superar el miedo a emprender acciones con las comunidades, fortaleciendo el liderazgos y la adquisición de habilidades para acompañar a otros/as. Ante el reto de conformar GAM, los/as promotores/as experimentaron inicialmente temor, inseguridad e inexperiencia, que luego se configuró en satisfacción y en la posibilidad de transformar su propio dolor mediante la fortaleza que confiere acompañar a otros/as, promoviendo la solidaridad, la ayuda y sensibilidad frente al dolor en sus comunidades:

...cuando empezaron a llegar y tuvieron disposición y todo se fue uniendo y fuimos viendo que sí se puede y que también tienen problemas y que también como hay problemas hay soluciones... fue muy bonito, tenían mucha disposición, entonces me gustó mucho, me dio mucha paz también, porque yo pensé que no iba a ser capaz, tenía mucho miedo, no iba a ser capaz (GF15). Yo vivía encerrada en mi problema, en mi dolor y no me importaba lo que le pasara al otro; como ya me había pasado, yo me encerraba, hoy en día digo: eso sirve, porque hay que concientizarlos de que hay que ayudarlos, si nosotros no nos ayudamos los unos a los otros, qué hay de esta sociedad (GF1).

Se ha fortalecido el liderazgo comunitario, adquiriendo herramientas para comprender su papel como líderes afectivos, con lo cual se alimenta el liderazgo político que algunos/ as participantes venían desarrollando, ya que se suma la capacidad de reflexionar sobre la necesidad de transformar las relaciones autoritarias y competitivas, por formas de acompañamiento de cooperación y afecto. El proceso permitió a su vez, aumentar la confianza en el trabajo desarrollado, mejorar la escucha, la apertura y el reconocimiento del otro/as como un ser digno, la empatía y la sensibilidad frente al dolor.

$Y$ así las acciones que vamos a hacer, que a ellos les beneficien también, porque no es lo mismo verlos como parte pues de una masa, sino que ya es su necesidad, la de cada cual... Soy lideresa y más bien me he confundido muchas veces, porque creemos que ser lideresas es ser directores, salvadores... Y no (GF3). Sacar un espacio para aquel que lo requiera, una buena escucha, porque es ahí donde se crea un verdadero acompañamiento para sacar aquel dolor (GF2).

Se posibilitó entonces reestablecer la confianza y la solidaridad, en medio de un ambiente acogedor y de aprendizaje mutuo que privilegia la palabra para expresar emociones e intercambiar experiencias, permitiendo descubrir alternativas y superar las propias dificultades con la fuerza que circula en el grupo. Por tanto, los GAM se convierten en escenarios sociales transformadores que potencias cambios posteriores, puesto que se establecen relaciones de solidaridad, horizontalidad y respeto que construyen cercanías y afectos (Villa, 2014aㅡ):... sabe algo muy lindo que he notado en mi grupo: la forma cómo ellas se retroalimentan, se dan fuerzas, ánimos, yo veía esta semana a una señora diciendo: haga 
MUTUAL SUPPORT, AFFECTIVE LEADERSHIP, AND COMMUNITY REHABILITATION. AN EXPERIENCE OF PSYCHOSOCIALACCOMPANIMENT FOR THE "REHABILITATION" OFVICTIMSOFTHEARMEDCONFLICT.

esto, no se preocupe, usted va a salir adelante, con esa fuerza, cómo ellos se fortalecen y se dan cuenta que sí se puede, eso es más gratificante todavía (GF1).

Así pues, podemos llegar a la conclusión que para los/as participantes el proceso logró tener un impacto comunitario, porque adquieren conciencia para identificarse como parte de un territorio con múltiples violencias, en el cuál están llamados/as a jugar un papel de transformación importante. A partir de sus propias transformaciones personales y cambios de actitud, aportan a romper cadenas de violencia y reconstruir el tejido de sus comunidades, en la medida en que se fortalece la tolerancia, la capacidad de establecer acuerdos, el sentido de colaboración, la confianza, afectividad y sensibilidad con otros/ as: ...estos procesos transforman las comunidades, cambian a la gente en el sentido en que la violencia, ya vienen con diálogos, la gente empieza a preguntar y el sólo hecho de uno hablarle a las personas sobre el proceso de paz, sobre que nosotras como mujeres tenemos que aportar algo, eso transforma a la gente en las comunidades (GF5).

El grupo se convierte en un contenedor de las experiencias, gracias a los vínculos establecidos; contribuye al crecimiento propio y la transformación colectiva, muy necesaria en el interior de un país marcado por la violencia, la desconfianza y la ruptura del lazo social. Por tanto, esta propuesta constituye una apuesta plausible para reconstruir el tejido social y tejer paz y reconciliación a través de transformaciones desde abajo, potenciando una reparación transformadora (Uprimny Yepes \& Guzmán Rodríguez, 2010):

... Yo creo que es una reparación muy importante independiente a la del Estado, es una reparación emocional, porque a nuestros grupos llegan personas muy decaídas, muy derrotadas, que estaban pensando simplemente en eso: -¿qué me da el Estado? Yo no estoy reparada, es una mentira, me han engañado. Pero en nuestros grupos, ha sido una reparación muy importante para ellas... ellas mismas lo dicen (GF4).

Se evidencia una vez más que los procesos deben ser desde abajo, con la gente y para la gente Martín Beristain, (1999) (2005) (2012) ; Villa, (2013b) (2014a)(2016), lo que requiere esfuerzos de las instituciones y de los profesionales, para que respondan desde una lógica más comunitaria, desde los recursos colectivos y el empoderamiento, trascendiendo la mentalidad tecno-burocrática que prioriza la planeación, el marco lógico, las metas y el cumplimiento de objetivos en un tiempo estimado (Duffield , 2004) ; (Villa Gómez, Arroyave, Montoya, \& Muñoz, 2016) Se trata de trabajar desde la corresponsabilidad y no la responsabilidad exclusiva del Estado, ya que deben potenciarse los propios procesos de la gente en una dinámica donde se pasa de un lugar de dependencia a uno de proactividad. Así, la reparación se convierte en una acción de reconstrucción subjetiva y colectiva, donde el paso de víctimas a ciudadanos/as implica un ejercicio personal y colectivo en el marco de una red de sanación, de un proceso de rehabilitación desde las comunidades:

A mí me parece que este proceso es buenísimo y que el sistema que hemos desarrollado en este proceso de acompañamiento psicosocial es el adecuado para mí... pienso que se debe hacer porque lo que se pretende es una renovación de la víctima, que su mente y su salud mental esté en el lugar apropiado. Yo pienso que esto se debe seguir haciendo de la misma manera, porque realmente lo que yo he vivido en el grupo, he visto personas cambiadas, actitudes renovadas. Entonces para mí, no continuar con esto, es como regar la semilla y dejar que se seque; esto tiene que fluir en toda la ciudad, porque lo que hemos vivido nos muestra que se puede tener un impacto muy poderoso sobre la ciudad de Medellín... el hecho de que la víctima sea sanada, también sana su familia, se tocan otras áreas importantes y se imparte a la ciudad una renovación de la salud mental (GF1). 


\section{Discusión.}

\section{Análisis de la propuesta pedagógica y el modelo de acción psicosocial como apuesta para la política pública de rehabilitación a las víctimas.}

A partir de los relatos analizados se ha visto que esta propuesta de acompañamiento psicosocial podría implementarse como parte de la política pública de rehabilitación en el marco de los procesos de reparación integral a víctimas del conflicto armado, en consonancia con la ley 1448 de 2011. De forma reflexiva, analizamos críticamente las dinámicas de los procesos de intervención psicosocial en el contexto del país, y las formas cómo la psicología y otras ramas del saber, deberían comenzar a tener apertura para vincularse con realidades sociales complejas, para proponer otros marcos epistémicos, otras metodologías que puedan desarrollar acciones transformadoras. Desde este lugar, junto con los/as participantes se reflexionó sobre las dinámicas pedagógicas de los grupos de apoyo mutuo, del proceso de formación de promotores y sobre la perspectiva psicosocial como dinamizadora de los ejercicios de rehabilitación de las víctimas en Colombia.

\section{Pedagogía lúdico-vivencial: nuevas metodologías y nuevas formas de aprendizaje.}

Este proceso empleó los principios, aplicaciones y metodologías de la pedagogía lúdicovivencial, acompañada de dispositivos simbólicos, estéticos y rituales, donde por medio del juego, ejercicios vivenciales, reflexivos y artísticos se generaron aprendizajes que posibilitaron una apropiación conceptual, más allá de la mera transmisión de información, mediante la recreación de los elementos teóricos a través de la experiencia. Así pues, se pretendía suscitar aprendizajes no sólo académicos, sino también para la resolución de situaciones de la vida cotidiana, así como brindar nuevas formas de ver y concebir el mundo y fomentar el crecimiento personal. Esta pedagogía motivó a los/as participantes para vincularse de manera integral con el proceso:

... pero lo más grandioso, es que han introducido un elemento que para uno es nuevo y es lo lúdico vivencial, ¿cierto? Entonces, esto también yo lo he experimentado como un proceso de sanación, yo de pronto no hablaba de mi caso personal, ¿cierto? Yo de pronto lo escribía, pero no lo he expresaba hacia afuera... Pero como es lúdico vivencial me han permitido a mí, expresar y experimentar sanación, y yo siento que he ido sanando, que yo he ido mirando el mundo y el entorno social de una manera más diferente... (GF3).

Esta metodología propicia otras formas de expresión diferentes a la palabra (dibujo, escritura, música, danza, etc.), que trascienden la apropiación conceptual y toca aspectos profundos del ser, facilitando la sanación emocional, en un marco de sentido que puede conceptualizarse como clínica comunitaria (Montero, 2011). Así, se ha posibilitado un proceso que va más allá de la tradicional "cura por la palabra", existiendo un profundo respeto por los ritmos de cada persona y por su capacidad de conexión o posibilidad de expresión; por lo cual se favorecieron formas expresivas que permiten compartir el afecto y el contacto, dando un lugar a las emociones y, al final, también a la palabra (Villa Gómez J. D., 2013a) (Villa Gómez J. D., 2014b)

Yo diría que de pronto en un psicólogo te ponen más que todo a hablar y aquí no es sólo hablar, sino que hay otros medios, hay el dibujo, la pintura, la escritura, entonces son otras formas de desahogarse y aliviarse, mientras que, en un psicólogo convencional, de pronto no te van a poner a hacer eso, yo diría que es una diferencia (GF15). 
Una relación terapéutica clásica está marcada por la neutralidad que no permite la implicación del profesional en el mundo de la vida y el contexto sociopolítico de los sujetos; mientras que el modelo de intervención y su propuesta pedagógica aquí formulada requiere una toma de posición frente a las injusticia y la violencia padecida por la gente, una solidaridad que lleva a una acción de defensa de derechos y una ruptura de la relación vertical "terapeuta/paciente", conduciendo a una relación horizontal que ubica al sujeto desde una perspectiva activa (Villa, 2013b).

Dicho modelo promueve la resistencia de la gente, el sentido de comunidad, y los vínculos afectivos que posibilitan la autogestión del bienestar (Montero, 2011); (Villa Gómez J. D., 2014b); más allá de las intervenciones externas, de la acción de la cooperación internacional y de la acción del Estado desde sus lógicas verticales de reparación (Villa Gómez \& Insuasty Rodríguez, 2015) (Villa Gómez \& Insuasty Rodríguez, 2016). Esta perspectiva opera en un marco de horizontalidad y genera una dinámica vincular que permite a las víctimas salir de su postración.

En este sentido, el arte pasa a ser una estrategia que subvierte la realidad impuesta por la fuerza, logrando conectar elementos no racionales del sujeto, como la emoción y el afecto; subvierte, además, prácticas socialmente aceptadas como la psicoterapia, que suele presentarse como una forma homogénea de transformar las experiencias traumáticas, reproduciendo la micropolítica de la salud mental (Pakman, 2011); (Pakman, 2014). Por tanto, el modelo propuesto propicia espacios estéticos, colectivos y afectivos que generan transformaciones subjetivas, mediante metodologías que trascienden las condiciones objetivas que rodean la vida cotidiana de los/as participantes y conducen a nuevas acciones para el desarrollo humano (González Rey, 2008). Así, cada persona podría expresar libremente los sentidos y significados que se transmitían por símbolos, en cuanto formas de representar emociones y sentimientos, lo que rescata el aspecto subjetivo y permite un flujo permanente entre "lo interno y lo externo", "lo psíquico y lo social", "lo individual y lo relacional", posibilitando una acción integral. Todo esto, facilita además la integración en los grupos de referencia social, de una manera crítica y creativa (Villa, 2014a):

Como la dinámica es lúdico vivencial y además es en grupos, entonces entra uno en contacto con el otro, la otra compañera, está uno con quien no se había imaginado ni siquiera que iba a estar. Entonces todo esto ha sido muy enriquecedor para mí... sí, muy enriquecedor, porque yo me siento abrigado, acompañado de los otros, ¿sí? (GF3).

Otro elemento de esta propuesta pedagógica son los rituales, que brindan la posibilidad de unión entre las personas, generando sentidos colectivos, identidad social, expresión de valores tradicionales, construcción de espacios y tiempos comunes, solución de conflictos internos y cierre y apertura de procesos; además, suscita cambios en la vida de las personas y las congrega en torno a eventos comunes significativos que favorecen la celebración de acontecimientos, "apenas quedan aspectos de la vida social que no se vean afectados por el ritual" (Nogués, 201, p. 5): Para mí todo ha sido muy importante, porque de todo lo que nos enseñan aprendemos y lo que me ha encantado mucho son los rituales, porque es una forma como de uno reflexionar sobre su vida, sobre lo que está haciendo y lo que uno ya debe transformar en positivo (GF5).

Durkheim (citado por Villa, 2014a), plantea que la participación en rituales funerarios, memoriales y conmemoraciones moviliza emociones (dolor, tristeza, cólera y rabia), lo que suscita reacciones positivas como la cohesión social, la integración y la solidaridad; lo que a su vez promueve procesos colectivos que propician la recuperación emocional (Martín 
Beristain, 2005; Villa, 2014b). Sin embargo, estos procesos colectivos pueden exacerbar, en un primer momento, emociones y rememoraciones de dolor, por lo cual algunos los expresan con temor y consideran que no promueven la recuperación (Páez et. Al., 1998):

Haber... yo pienso que hay rituales que no... hay personas que dicen que algunos los dejan muy mal... los marca mucho y no deberían de ser, porque por ejemplo eso de la muerte... de recordar el ser querido... eso no. En cuanto a la forma por ejemplo de abordarse, debería ser diferente, porque eso que del traje negro... son cosas que pueden indisponer, y para mí eso no era como para sanar (GF2).

No obstante, si se da un proceso que enmarque los actos y ritos en un trabajo a largo plazo que implique: acompañamiento, proceso grupal, fortalecimiento colectivo y organizativo; pueden generarse transformaciones a partir del contacto con la emoción profunda que se logra en el ritual o acto simbólico. Por ello, la mayoría de participantes reconoce que, si bien el ritual suscita emociones y recuerdos dolorosos, ayuda a reconocer sentimientos para expresarlos, sobretodo porque en la vida cotidiana suele vetarse la posibilidad de expresión: Yo pienso que si bien a la compañera puede que no le hayan gustado, pero a otros sí, porque puede que para algunos pueda ser muy triste recordar, también el hablar y recordar va ir sanando que cosas que de pronto uno tenía ocultas y aquí lo sacamos (GF2).

De esta forma, lo que se quiere es generar aprendizajes y vivencias significativas que generen mayor bienestar emocional, recuperación de la confianza, conexión profunda consigo mismos, con los otros y con el medio; conectando al grupo con dimensiones que son propias y necesarias para la salud mental como la diversión, lo lúdico, lo espiritual y el propio cuerpo (Villa, et. al. 2015):

Pues yo creo que todo ha sido pertinente, porque en primer lugar la salud emocional de las personas debe ser más importante que la física, porque a usted le duele un pie y bueno sintió el dolor, fue donde el médico y se le quitó porque sí. Pero emocionalmente, si usted está mal, pues va a estar mal usted, su familia y el entorno... creo que todo lo que hemos visto aquí: los rituales, dinámicas, todo de alguna manera nos ha servido, nos va a servir más adelante. Para mí todo antes ha sido poquito, y en este país, pues no sé, nunca se han preocupado por lo que el otro siente, simplemente la arrinconan a un lado, diciendo aquél si molesta o aquél que parece loco... (GF5).

Este relato conecta con la visión de salud planteada en la Carta de Ottawa de 1986, cuando alude que "la salud es el resultado de los cuidados que uno se dispensa a sí mismo y a los demás, de la capacidad de tomar decisiones y controlar la vida propia, y de asegurar que la sociedad en que uno vive ofrece a todos sus miembros la posibilidad de gozar de un buen estado de salud." OMS (citado por Mantilla, s/f). Este modelo de intervención opta, por tanto, por una concepción integral del ser humano, donde no existe separación entre el cuerpo, la mente y su relación con el entorno. De otro lado, se evidencia la fuerza del apoyo social como metodología para propiciar escenarios de promoción de la salud mental, además de prevención y sanación de procesos sintomáticos a nivel psíquico y físico, que están relacionados con órdenes contextuales, más que con factores internos (Gracia Fuster, 2011). Por tanto, este tipo de propuestas pedagógicas permiten crear espacios donde las personas aporten a su propia salud mediante el cuidado de sí mismos y del otro, desarrollando sus potencialidades, a partir de la autonomía, la libertad y el compromiso como miembro activo de la sociedad; con lo cual se entra al plano de una reparación transformadora (Uprimny Yepes \& Guzmán Rodríguez, 2010). 
MUTUAL SUPPORT, AFFECTIVE LEADERSHIP, AND COMMUNITY REHABILITATION.

AN EXPERIENCE OF PSYCHOSOCIALACCOMPANIMENT FORTHE "REHABILITATION" OFVICTIMSOFTHEARMEDCONFLICT.

\section{Del experto en la razón instrumental al acompañante en la razón compasiva.}

Ligado a los planteamientos enunciados en el acápite anterior, muchos de los/as participantes, refieren haber podido resignificar sus experiencias frente a la atención psiquiátrica y psicológica tradicional, que está atravesada por una visión que privilegia la patología, la medicación y los espacios individuales de intervención; en la medida en que ellos/as han encontrado en los GAM formas alternas de relación y metodologías de trabajo que rescatan a la persona en contexto y en relación con otros:

Lo primero que a mí me mandaron fue medicación y me dio, personalmente, una tristeza tan grande... que yo recibí la medicación, incluso fui mensualmente por ella, pero nunca me llegué a tomar una pastilla, sino que yo me dediqué fue a preguntarle a las personas... Pero aquí, en especial a mí me llamó la atención tratar este tema, no desde la medicación, sino desde el contexto. Y eso a mí me enriqueció... Entonces eso fue una curiosidad en que me alcancé a identificar, porque me parece que es demasiado saludable. Es más saludable decirle a una persona: "Qué tal si nos pegamos una conversadita... si nos acompañamos, si voy y estoy allá... yo no sé qué va a pasar, ni qué vamos a hacer, pero voy a estar allá" ... Hablando de mi tema personal, del desplazamiento... (GF3).

Además, las personas encuentran otro tipo de estrategias que van más allá del espacio del consultorio, las cuales destacan un escenario grupal donde, por medio del afecto y la relación con otros, se les permitió empoderarse de sus sentidos vitales y salir de la postración (Villa, 2014a), es decir, de la parálisis en la que se pierde cualquier posibilidad de acción, puesto que se termina actuando según la voluntad del actor armado:

...hay mucha diferencia, porque los profesionales son como de escritorio, de llenar una ficha, qué fue lo que te pasó, contame tu historia y ya... Ahí se quedó plasmado en un papel, que, si llenó la ficha, que sí asistió, que sí te atendió, firme aquí y pico y chao. Entonces si la persona está demasiado postrada, demasiado neurótica, entonces ya no necesita psicólogo, ya necesita es psiquiatra, entonces pa' que lo manden y lo empepen, pa' que lo pongan a dormir día y noche, que lo pongan como un bobo, ya... eso es todo. Mientras que acá no necesitamos ni una pastilla, necesitamos, pero de dosis de pintura, de conversación, de risas, de alegría, de experiencias, de abrazos, de herramientas; de eso tuvimos muchas dosis acá, pero no de pastillas, no nos pusieron como un bobo a dormir día y noche (GF5).

Das (2008), Basabe (2001), Lykes (2001a) (2001b) Martín Beristain (1999) (2005) (2012) Villa et. al. (2007) (2012), Villa (2013a) (2014a) (2016a), piensan que la estrategia de apoyo mutuo entre las personas que han sufrido el horror, puede ser más efectiva que otras formas de intervención, puesto que posibilita ese primer paso de la contención y expresión; además, permite una relación diferente, enmarcada en un proceso colectivo, donde los/ as participantes no han sido individualizados, sino que hacen parte de un colectivo que ha padecido la guerra. Así pues, el GAM se convierte en escenario que posibilita además la seguridad y la confianza, el afrontamiento del miedo y la creación de otros lenguajes posibles que trascienden ciertos formatos de la palabra, en un proceso de escucha, acogida, contención y reconocimiento que, en lo narrativo o en lo performativo, han posibilitado que la experiencia del horror no se quede ni en el olvido, ni en el anonimato, ni en lo privado.

Los miembros de un GAM entre iguales son parte de un colectivo que comienza a vivir la experiencia de reconstrucción de redes rotas y a restablecerse en un proceso que necesita tiempo y espacio; donde lo fundamental no está en el resultado, ni en la ejecución de 
actividades, sino en la dinámica de asumirse a sí mismo como sujeto con dignidad, que puede retomar el control de su vida y su destino (Nets-Zehngut \& Bar-Tal, 2007). El GAM se teje entre iguales, personas con experiencias comunes, que se identifican y logran sentirse comprendidas; reconstruyendo el tejido social que han desestructurado los grupos armados (Villa,2014b).

Este proceso tiene en cuenta el lugar bisagra de los sujetos, entre su dimensión emocional y su dimensión social (Martín Baró, 1983), lo que ha posibilitado transformaciones profundas: donde lo que está oprimido o reprimido emerge lentamente con libertad (Villa, 2013b). Se deja de considerar al otro como una amenaza y se convierte en un compañero de camino, se adquieren nuevos significados y actitudes respecto a las experiencias compartidas de dolor, creando un tejido donde todos/as se potan en un proceso de sanación:

Estos son más reparadores que el psicólogo particular porque conocemos el problema de cada uno y ven que el problema mío sí es duro, pero hay problemas más graves que lo que a uno le pasó. Y eso le va enseñando a uno a engranar y tener el motorcito que va girando, me voy sanando yo, se va sanando ella, con lo que ve que yo hago, con lo que yo he mejorado, y así sucesivamente (GF11).

Sin embargo, no se desconoce el espacio individual como forma de seguir promoviendo la creación de sentidos y significados que generen transformaciones. Por tanto, lo grupal y lo individual se conciben como dimensiones complementarias y articuladas. De hecho, desde una perspectiva psicosocial, los procesos de atención individual, grupal y/o comunitaria no son la unidad diferenciadora entre una intervención psicológica o clínica y una intervención social; sino que desde una visión sistémica, se considera que la acción con el sujeto implica la intervención en sus micro, meso y macrosistemas y que la intervención en los sistemas de relación interpersonales, grupales, colectivos y sociales tiene redundancia explícita en el sujeto (Bronfenbrenner, 1987) ; (Musitú, 2004), de tal manera que podemos hablar de intervenciones psicosociales en los individuos y de una clínica comunitaria (Montero, 2011):

...Nosotros hemos contado con la ayuda de la psicóloga, es muy querida nos ha ayudado mucho, pero ellos realizan un trabajo más personal y este es además de personal, grupal; es estar ahí, mirar al otro, perdonar, pedir perdón, trabajar los valores, los dos procesos nos ayudan mucho, pero las dinámicas de trabajo son muy diferentes (GF7).

Así, desde una perspectiva histórico-cultural, realizamos lecturas diferentes del proceso terapéutico a las que se realizan en la psicología tradicional patologizante, lo que abre nuevas posibilidades de relación terapéuticas, más allá de las teorías concretas, que exigen creatividad y autenticidad para generar nuevas opciones de subjetivación y abrir nuevas "zonas de sentido", nuevas formas de relación y subjetivación. Se trata entonces de una concepción más completa del sujeto, que considera importante reconocer lo que sucede con cada participante desde sus vivencias y promueve relaciones que permitan la apertura hacia formas posibles de pensarse, ser y hacer (González Rey, 2009).

De allí que muchos/as de los/as participantes, al comparar escenarios tradicionales de intervención psicológica con este proceso, señalaran que en los primeros se encontraban con profesionales que orientaban su trabajo desde un lugar de saber, como aquel que conoce y cree tener la razón, con quien sienten una distancia y que no tiene en cuenta sus necesidades y vivencias. Villa (2012) (2013b) describe este marco de relación como vertical, donde el saber juega un lugar de poder y no posibilita un encuentro con el otro desde la cercanía y el afecto, por tanto, ese otro no logra ser parte activa. De otro lado, en 
MUTUAL SUPPORT, AFFECTIVE LEADERSHIP, AND COMMUNITY REHABILITATION.

AN EXPERIENCE OF PSYCHOSOCIALACCOMPANIMENT FORTHE "REHABILITATION" OFVICTIMSOFTHEARMEDCONFLICT.

el proceso de apoyo mutuo y en la pedagogía lúdico- vivencial se encuentran marcos de relación horizontal que genera interacciones de construcción conjunta y de transformación subjetiva y colectiva como los que han sido descritos:

Lo digo de forma respetuosa, muchos profesionales no lo hacen, ellos creen que solamente es el concepto de ellos, que se la saben toda y que el saber de la comunidad no es. Y aquí lo que nos generan es confianza y los protagonistas son los participantes, y muchas veces en otros procesos los participantes no son los protagonistas, sino los psicólogos; porque ellos se muestran como los talleristas, los conferencistas, y resulta que aquí hay que cambiar de rol, para que este proceso pueda tener unos verdaderos resultados y la gente realmente pueda levantarse de donde está, porque si a nosotros no nos hubieran inspirado confianza, téngalo por seguro que la mayoría hubiéramos desertado de este proceso (GF2).

Por tanto, para fortalecer las intervenciones que se vienen desarrollando en los procesos de rehabilitación y reparación, desde las agencias del Estado, se requiere un cambio en la concepción del rol del profesional, para que pueda facilitar transformaciones y permitir que los otros se levanten del lugar de postración en el que están. Esto implicaría acciones integrales, que además de trascender la burocracia, trasciendan los esquemas y marcos conceptuales de los expertos, para poner en diálogo los saberes profesionales con los de la gente; de tal manera, sin demeritar el aporte de profesionales y de las disciplinas, se reconsidere el saber y valor de la gente y la forma como han construido estrategias de sobrevivencia, resistencia, desarrollo, recuperación, reconstrucción y dignidad Villa (2013b) (2016); (Villa, et al, 2016). Por ello los relatos abogan por procesos de acompañamiento psicosocial que generen acogimiento, respeto, escucha, confianza y libertad para hablar sin ser juzgados, señalados o diagnosticados desde la patología, que desconoce las historias de vida marcadas por violencia y horror:

Para mí en este proceso, lo que más me ha gustado fue ese respeto que tiene con nosotras las víctimas, en donde todas tenemos la libertad de hablar, de nuestras necesidades, de todas nuestras cosas, sin haber un señalamiento... es un ambiente de confianza y de respeto, en donde uno se siente bien, y tiene la necesidad, porque ejemplo, lo que soy yo, el día martes es un día especial, porque sé que vengo y puedo aprender más (GF2).

Este marco de acción implica una posición de escucha y apertura, un interés genuino por la experiencia del otro, fomentando el contacto corporal, el abrazo, el afecto, en una palabra, el amor, como expresión donde el otro es un legítimo otro (Maturana \& Verden - Zoller, 1993) y se le expresa que se le quiere y acoge. Muchos lo nombran como calidez humana, lazo o cercanía, en contraposición con un modelo biomédico que distancia a los sujetos del profesional y los ubica en el lugar de enfermos y traumatizados; en nuestra reflexión con los/as participantes, son estos los factores diferenciales que potencian los procesos de recuperación y que necesitan las comunidades:

...La diferencia principal ha sido el lazo de compenetración... que se ha cimentado en dar esa confianza, en dar esa oportunidad de ser escuchado con esa calidez humana, no con esa división de enfermo mental y de profesional, tú en tu lugar y yo acá escuchándote... -cuéntame, cuéntame, cuéntame-. Y... con la actitud tan lejana si le está importando o no, lo que yo le estoy diciendo. Esa ha sido la diferencia que yo puedo recalcar. El psicólogo llega y se sienta y... empieza a pensar por allá... y la persona diciendo las cosas... entonces no hay ese contacto, de que si lloró cómo se siente, del abrazo que nosotros necesitamos, entonces esa es la diferencia que yo he sentido (GF2). 
Es importante el hecho de que la mayoría de las personas que hicieron parte de este proceso han tenido contacto con psicólogos que, dadas las características de los procesos institucionales, principalmente los estatales, exigen el cumplimiento de metas o cifras consideradas como más importantes que el proceso de la persona. Así el profesional se institucionaliza y pierde interés por el bienestar del otro, cayendo en el asistencialismo que han tenido los procesos de reparación en el país (Villa Gómez \& Insuasty Rodríguez, 2015) (Villa Gómez \& Insuasty Rodríguez, 2016)

...siempre en un proyecto, siempre son metas y más metas, entonces yo digo, que hasta la misma sociedad se encarga de transformarlo a uno, que siempre son metas, pero no entienden que una persona también está pasando por muchas cosas, que si yo envío una psicóloga a un hogar donde hay diferentes problemáticas, muchos riesgos, porque no le enseñan a esa persona a ser al menos un poquito más comprensiva, dar ese calor como decíamos, darle ese calor humano a las personas. (GF4)

De acuerdo con Villa, et al (2016), pareciera haber dos configuraciones de tiempo, uno es el tiempo de la gente, el de la comunidad, incluso el tiempo del daño percibido; otro es el tiempo de la lógica instrumental que está implicada en la mirada metodológica, desde la planeación y ejecución de proyectos, la cual es lineal, que parte de un objetivo y se dirige hacia su cumplimiento, sea lo que sea y pase lo que pase; de modo similar al proceso tayloriano de producción, organización de tiempos y movimientos. Esa es una lógica y es válida en ciertos contextos de tipo productivo y financiero; pero cuando aplica a los procesos humanos, todo el personal termina corriendo para cumplirle a un indicador o un resultado; lo que puede generar daño, porque se tiene que demostrar en muchos casos que "se atendieron" a "X" número de personas en una cantidad de tiempo (Bello, 2005) (Villa, 2016a).

La paradoja es clara: a pesar del intento de una planificación detallada del tiempo, a través de la planeación estratégica y de los cronogramas de trabajo, éste escasea para que los profesionales puedan construir con las comunidades lo que Veena Das (2008) llama una "comunidad moral", es decir un proceso social de escucha y apoyo como el que se viene presentando; que, es fundamental para desarrollar procesos de atención y reparación integral. Así pues, de acuerdo con Villa, Arroyave, Montoya \& Muñoz (2016) se puede terminar generando, también en los/as profesionales, un sentimiento de incompletud, que se asocia a una sensación de fugacidad en las intervenciones, que terminan siendo vistas, por ellos mismos, como acciones superficiales; puesto que evidencian que en muchas ocasiones el dolor, el sufrimiento y las realidades desestructurantes de los sujetos y las comunidades siguen sin transformación.

La diferencia si es mucho, porque cuando uno va a consulta donde un psicólogo, en primer lugar, el tiempo es medido, lo primero es tomar los datos, escriban y escriban y si está de malas le toca examen (test psicológico), lo contesto, lo que le dicen a uno es échele tierra a eso y hay que empezar de nuevo. En cambio, aquí, pues yo trabajo con los otros desde lo profundo, es como cuando usted va a sembrar la caña, que primero las raíces y poco a poco, que también se abona con algo, porque no es lo mismo usted hablar con un psicólogo que la acaba de ver, que con una persona que usted tiene oportunidad de compartir todo el día, que son personas que le brindan confianza a uno, que no es como la que está allá y dígame qué le pasa y eso no es fácil, uno contándole algo a un desconocido. Porque yo creo que a nosotros nos pasó eso con los grupos, que ellos no se soltaron de una como se dice, sino que eso fue poco a poco; entonces yo digo que la diferencia fue mucha, imagínese tenemos todo un día para estar con ellas, entonces la diferencia es mucha (GF5). 
Siguiendo a Villa, et al (2016) cada persona, cada comunidad es una historia, es un mundo de significación; cada lugar es una idiosincrasia, una cultura, un tiempo de acercamiento. Son personas afectadas que se acostumbraron a callar, que tienen miedo, que desconfían de todo y de todos porque esto les ha permitido sobrevivir; es decir, volvemos al contexto, a la situación, donde las cosas son más complejas y hay personas que necesitan más tiempo, hay mucha más gente que la esperada y en la vida de la gente las cosas son de otra manera. Las personas y las comunidades son más que víctimas, son más que eventos violentos, son historias de resistencia, de dignidad; por tanto, no tiene por qué adaptarse a los tiempos y procesos marcados desde una razón instrumental (Blanco \& Gaborit, 2007).

Lo primordial en los procesos de reparación sería "sanar el alma", lo que implica que los proyectos y profesionales involucren su sentir y que orienten su acción desde una razón compasiva (Blanco \& Gaborit, 2007), en una relación horizontal que confiera protagonismo a los/as participantes en sus procesos de rehabilitación y no sólo las convive para firmar una hoja de asistencia y seguir instrucciones:

Aquí hay una cosecha de gente con corazón latente, yo no estoy diciendo que todos los funcionarios son malos, ellos hacen su trabajo por el cual les pagan y de pronto, tienen su trabajo para ellos bien, pero sin calor humano, no los mueve el dolor ajeno, no los mueve el deseo de ayudar, es sólo un empleo donde les pagan por eso. Aquí, hay en cantidades lo que no se consigue en otras partes, ese diplomado y los GAM, se deberían replicar en todas las partes del mundo donde hay conflicto, porque dicen que nos ayudan con un mercado, con fortalecimiento para que nos volvamos productivos, pero si uno no ha sanado el dolor, eso no fluye, eso no prospera, primero hay que sanar el alma (GF1).

Para los/as participantes los profesionales involucrados en este proceso necesitan compromiso, sentido de vida, una vocación y una opción vital, tal como también lo han enunciado Villa, Arroyave, Montoya \& Muñoz (2015), que agregan la importancia de tener claro el contexto, abrir puertas al afecto, a la relación y al encuentro. Para los/ as participantes de esta sistematización, estas condiciones deben mantenerse en otros espacios:

Uno ha ido a muchas partes, pero es todo, todo, teoría: el señor en el estrado y uno ahí, escuche y escuche, ni siquiera se despiden cuando se van a ir, aquí se preocupan porque no vino uno, qué le pasó, vamos a ver cómo le solucionamos, es todo eso, es el calor, es el sentir que uno percibe, eso es la diferencia y eso es lo que tenemos que cultivar, porque no podemos dejar morir esa llamita que está surgiendo (GF1).

De hecho, Villa, et al. (2015) en voz de los profesionales que trabajan en estos contextos, lo refuerzan afirmando que los/as profesionales que Colombia necesita para acompañar a las personas afectadas por el conflicto armado, tendrán que tener o desarrollar, además de las competencias académicas y profesionales tradicionales, convicciones que los vincule con la protección de los derechos humanos, el empoderamiento de las personas y comunidades, la transformación social y política de situaciones de violencia, opresión y explotación; lo que requiere una posición subjetiva y un lugar ético y político, más allá de la neutralidad profesional, profesada en muchas de las aulas de las universidades, un conocimiento profundo y una implicación real y afectiva con los contextos. Debe además ser capaces de confrontar las lógicas de la tecnocracia y la burocracia de los proyectos institucionales, más allá de la tensión de su "seguridad" laboral, que no cifren el interés en las metas, resultados, cifras y el formato, para construir auténticas relaciones de apoyo y acompañamiento (Villa, 2016) (Villa et al.2016). 
Por esto, se hace necesario el desarrollo de habilidades básicas como la empatía, la escucha, la horizontalidad, la contención, entre otras, que son sencillamente recursos de lo humano, que en una sociedad atravesada por la lógica racionalista instrumental y por las diversas formas de control y violencia han quedado relegadas al ámbito de lo privado. Como lo plantea Rogers (1973): todo ser humano tiene un potencial natural hacia el crecimiento que se puede liberar si se dan las condiciones adecuadas: cuando se confía en la persona para que haga elecciones y encuentre el valor para tomar decisiones responsables, ésta empieza a cambiar su propio mundo. La liberación de estas potencialidades tiene que ver con el ser genuino, con la autenticidad; en definitiva, con la espontaneidad. Cuando la persona se siente en un entorno en el que no es juzgada, donde es aceptada incondicionalmente, de manera natural, se da lugar a una persona más auténtica. Y en nuestro concepto esto es válido, tanto para los profesionales, como para los y las participantes de los proyectos de reparación.

\section{Conclusiones.}

Puede decirse, con Martín Beristain \& Rieira (1994) y con González \& Villa (2012), que el acompañamiento psicosocial desde abajo, a través de la formación de líderes afectivos, con metodología del grupo de apoyo mutuo (GAM), desde una pedagogía lúdico-vivencial, es un espacio colectivo donde se recupera el papel social activo de los/as participantes, se construyen relaciones de confianza, se configura un espacio adecuado para compartir sentimientos y emociones abiertamente, se comprenden y transforman las situaciones vividas en el momento, a nivel individual y/o comunitario (Martín Beristain, 2014); se resignifican experiencias de dolor, reconociendo que el daño fue para una buena parte de la población, lo que suscita solidaridad y apoyo (Hamber, 2011) (Martín Beristain, 2005) (Fulchiron, 2011); además, se analiza la realidad para afrontarla con más y mejores recursos, promoviendo el empoderamiento personal y comunitario y la reconstrucción del tejido social.

La dinámica relacional que emerge en el GAM se constituye en la posibilidad de comprender y de conectarse con la historia, de lo cual emerge la resiliencia, como resistencia frente a la destrucción y como capacidad de construcción y reconocimiento de fortalezas, más allá de la vulnerabilidad (Mallarino \& Arias, 2003). Es entonces cuando se puede decir que las personas comienzan a salir de la postración y a recuperar su lugar como humanos que sienten y que son libres de tomar decisiones en torno a la actitud que asumen para vivir.

Esta metodología constituye un ejercicio de inclusión en el que participan personas pertenecientes a distintos sectoresy en diferentes momentos de su desarrollo vital,y posibilita el fortalecimiento de lazos afectivos personales y colectivos, generando nuevos ejercicios de convivencia en las comunidades y familias. En los GAM se vivencian "encuentros genuinos" (Martínez, 1982) en el marco de las relaciones comunitarias cotidianas, en procesos de reconocimiento mutuo y de fortalecimiento desde abajo; configurando escenarios terapéuticos comunitarios, es decir, un ejercicio de una clínica comunitaria (Montero, 2011) capaz de ampliar su cobertura, sacar a la psicología del consultorio, pero también superar la llamada intervención social de la lógica del taller estereotipado; demostrando que las transformaciones subjetivas no operan tanto por las técnicas aplicadas a partir de marcos teóricos, sino en los procesos de reconstrucción del lazo social y los vínculos fundamentales en una lógica de amor, contención y apoyo mutuo.

Desde nuestro punto de vista, el ser humano sólo se hace y se desarrolla en relación con otros, es por ello que las relaciones de apoyo brindan a la persona un espacio auténtico para 
que logre su adecuado desarrollo. En línea con esto, autores como Rogers (1973)consideran que lo que posibilita el desarrollo de las potencialidades, es la relación que se instaura entre los sujetos que entran en juego en la relación de ayuda. Por ende, la transformación subjetiva, tanto de las personas que han sido víctimas como de los profesionales que las acompañan, requiere un movimiento bidireccional, que involucre a ambas partes y que conduzca a un diálogo de saberes, a un empoderamiento colectivo y personal, que dé lugar a la recuperación de la dignidad y a la reconstrucción del tejido social (Villa, 2014). Para ello hay que salir de la queja y construir propuestas y acciones coherentes con la experiencia presentada en esta sistematización; la cual para los/as participantes debería tener continuidad.

De igual forma, en nuestro concepto y en una sociedad donde ha permanecido durante tantas décadas el conflicto armado y se han naturalizado formas violentas de relación, este tipo de ejercicios psicosociales, basados en el apoyo mutuo, en una clínica comunitaria (Montero, 2011), donde se humanizan y dignifican personas, deben tener continuidad y expandirse hacia otros espacios y territorios, constituyéndose en una estrategia fundamental para la medida de rehabilitación en el proceso de reparación propuesto por la Ley 1448 de 2011. Sorprende aún que el Ministerio de Salud, con su programa PAPSIVI o la UARIV no hayan acogido decididamente esta apuesta como fundamental en sus programas y proyectos, más allá de algunas acciones cosméticas. Para nosotros es el camino por el cual las intervenciones psicosociales y los procesos de rehabilitación de las víctimas, podrían comenzar a generar cambios significativos en las vidas de las personas. Por tanto, se hace necesario que las instituciones de la salud y quienes desarrollan las políticas de reparación puedan prestar atención a la evidencia presentada y a los procesos exitosos desarrollados en diversos contextos (regionales, urbanos, rurales) del país, intentando acompasar sus lógicas basadas en la razón instrumental y la tecnoburocracia con las lógicas de las comunidades, para generar procesos, programas y proyectos que vayan más allá de la linealidad de la contratación, los tiempos de ejecución, las metas, los indicadores y resultados; posibilitando dinámicas que realmente contribuyan a la reconstrucción del tejido social desde la gente, sus tiempos, sus sentires, sus significados, sus marcos simbólicos y sus sentidos de vida. Si esto es posible y si hubieran "funcionarios" capaces de ir más allá de la conservación de sus puestos, se daría un paso fundamental para la reconstrucción del país, la transformación subjetiva y la construcción de la paz y la reconciliación, abriendo nuevos horizontes, tanto en la vida cotidiana, como en la vida pública de nuestra nación. 


\section{Referencias bibliográficas.}

Aron, A. (1992). Testimonio' a bridge between psychotherapy and sociotherapy. En E. Cole, O. Espin, \& E. Rothblunm, Refugee women and their mental health (págs. 173 190). Bingharnton: The Harthow Press.

AVRE. (2002). Proceso de formación de terapeutas populares y multiplicadores en acciones psicosociales en un contexto de violencia sociopolítica. Bogotá: AVRE.

Bar-Tal, D. (2000). From intractable conflict through conflict resolution to reconciliation: psychological analysis. Political Psychological, 21(2), $351-365$.

Bar-Tal, D. (2003). Collective Memory of physical violence: its contribution to the culture of violence. En E. Cairns, \& M. D. Roe, The Role of Memory in ethnic conflict. Macmillan, New York: Palgrave.

Basabe, N. (2001). Violencia, apoyo a las víctimas y reconstrucción social. Reflexiones en torno al caso vasco. En C. Martín Beristain, \& D. Páez, Violencia, apoyo a las víctimas y reconstrucción social. Debates y desafíos en el caso Vasco. Seminario Internacional, comunicación interna.

Bello, M. N. (2005). Bojayá, Memoria y Río. Violencia política, daño y reparación. Bogotá: Editorial UNIBIBLOS.

Blanco, A., \& Gaborit, M. (2007). La razón compasiva y la acción como ideología: una nueva mirada a la psicología de la liberación. Comunicación interna de los autores.

Bronfenbrenner, U. (1987). Ecología del desarrollo humano. Barcelona: Paidós.

Das, V. (2008). Lenguaje y cuerpo: Transacciones en la construcción del dolor. En F. Ortega, Veena Das: Sujetos del dolor, agentes de dignidad (págs. 343 - 374). Bogotá: Pontificia Universidad Javeriana y Universidad Nacional de Colombia.

Duffield, M. (2004). Las nuevas guerras en el mundo global. Madrid: La Catarata.

Flick, U. (2004). Introducción a la investigación cualitativa. Madrid y A Coruña: Ediciones Morata y Fundación Paideia.

Freud, S. (1915/1917). Duelo y Melancolía. Buenos Aires: Amorrortú Editores.

Fulchiron, A. (2011). Tejidos que lleva el alma. Guatemala: Actoras de cambio.

González Rey, F. (2008). Psicología y arte: razones teóricas y epistemológicas de un desencuentro. Brasil: Centro Universitario de Brasilia.

González Rey, F. (2009). Psicoterapia, Subjetividad y Postmodernidad. Buenos Aires: S.R.L.

González Rey, F. (2011). El sujeto y la subjetividad en la psicología social. Un enfoque histórico cultura. Buenos Aires: Noveduc. 
MUTUAL SUPPORT, AFFECTIVE LEADERSHIP, AND COMMUNITY REHABILITATION. AN EXPERIENCE OF PSYCHOSOCIALACCOMPANIMENT FOR THE"REHABILITATION" OFVICTIMSOF THEARMED CONFLICT.

Gracia Fuster, E. (2011). Apoyo social e intervención social y comunitaria. En I. Fernández, J. F. Morales, \& F. Molero, Psicología de la intervención comunitaria (págs. 129 171). Bilbao: Biblioteca de psicología, Desclée de Brower UNED.

Hamber, B. (2008). Trauma, development and peacebuilding: towards an integrated psychosocial approach. Belfast: Incore - IDRC, Unisersity of Ulster.

Hamber, B. (2011). Transformar las sociedades después de la violencia política. Verdad, reconciliación y salud mental. Barcelona: Instituto Catalán Internacional para la Paz.

Herrero Oalizola, J. (2004). La perspectiva ecológica.En G. Musitú, J. Herrero, E.Cantera, \& M. Montenegro, Introducción a la psicología comunitaria (págs. 55 - 77). Barcelona: UCO.

Kaufman, S. G. (2006). Lo legado y lo propio. Lazos Familiares y transmisión de memorias. En E. Jelin, \& S. Kaufman, Subjetividad y Figuras de la memoria (págs. 47 - 71). Madrid: SigloXXI.

Lira, E. (2011). El testimonio de experiencias políticas traumáticas: terapia, denuncia y memoria. En M. L. Rappacci, Notas en clave de psicología (págs. 29-48). Bogotá: Editorial javeriana.

Lira, E., \& Castillo, M. I. (1993). Trauma Político y Memoria Social. Revista de Psicología Política, 95 - 116.

Lykes, M. B. (2001a). A critical re-reading of PTSD fron a cross-cultural community perspective. En D. Hook, \& G. Eagle, Psychopatology and social predjudice (págs. 92 - 108). Cape Town, South Africa: UCT pres / JTA.

Lykes, M. B. (2001b). Artes Creativas y fotografía en investigación-acción-participativa en Guatemala. En R. Reason, \& H. Bradbury, Handbook of action research (págs. 363 - 371). London: Sage.

Mallarino, M. A., \& Arias, G. (2003). Ventanas Abiertas. Pedagogía con afecto y libertad. Bogotá : Editorial Planeta Colombiana S. A.

Mantilla, B. P. (s.f.). Salud integral: evolución del proceso y propuesta actual. Obtenido de escpromotorasdesalud.weebly.com: http://escpromotorasdesalud.weebly.com/ uploads/1/3/9/4/13940309/salud_integral_evolucin_y_propuesta.pdf

Martín Baró, I. (1983). Acción Ideología. Psicología social desde Centroamérica. San Salvador: UCA editores.

Martin Beristain, C. (1999). Reconstruir el tejido social. Barcelona: Icaria.

Martín Beristain, C. (2005). Procesos de duelo en las comunidades mayas afectadas por violencia política. Tesis en psicología social. Bilbao: Universidad del País Vasco.

Martín Beristain, C. (2006). Reconciliación Luego de Conflictos Violentos: un marco teórico. En Verdad, Justicia y Reparación, desafíos de la democracia y la conviviencia social. San José de Costa Rica: IDEA e IDH. 
Martín Beristain, C. (2007). Reconstrucción del tejido social. Aprendizajes y desafíos desde la experiencia guatemalteca. En: El legado de la Verdad: Impacto de la justicia transicional en la construcción de la democracia en América Latina. Bogotá: Centro Internacional de Justicia Transicional (ICJT).

Martín Beristain, C. (2008). Memoria colectiva y reconstrucción de sociedades fracturadas por la violencia. En M. Romero, Verdad, memoria y reconstrucción: Estudios de caso y análisis comparado (págs. 329 - 342). Bogotá: Centro Internacional de Justicia Transicional (ICTJ).

Martín Beristain, C. (2012). Procesos psicosociales con víctimas de la violencia política. Comunicación interna.

Martín Beristain, C. (2014). Acompañar los procesos con las víctimas. Bogotá: Fondo de Justicia Transicional.

Martín Beristain, C., \& Riera, F. (1994). Afirmación y Resistencia. La comunidad como apoyo. Barcelona: Virus editorial.

Martínez, M. (1982). La psicología humanista: fundamentación epistemológica, estructura y método. México: Editorial Trillas.

Maturana, H., \& Verden - Zoller. (1993). Amor y Juego. Fundamentos olvidados de lo humano, desde el patriarcado a la democracia. Santiago de Chile: Editorial Instituto de Terapia Cognitiva.

Montero, M. (2011). Procedimientos y herramientas terapéuticas en contextos de pobreza. El método clínco-comunitario en construcción. En A. E. Hincapié, Sujetos políticos y acción comunitaria (págs. 221-247). Medellín: UPB.

Nets-Zehngut, R., \& Bar-Tal, D. (2007). Nets-Zehngut, R. \& Bar-Tal, D. (2007) The intractable Israeli-Palestinian conflict and possible pathways to peace. En J. Kuriansky, Beyond bullets and bombs: Grassroots peacebuilding between Palestinians and Israelis (págs. 3 - 13). Westport: CT: Praeger.

Nogués, A. M. (2015). El ritual como proceso. Obtenido de www.dip-alicante.es: http://www. dip-alicante.es/hipokrates/hipokrates_i/pdf/ESP/435e.pdf

Páez, D., Basabé, N., \& González, J. L. (1998). Memoria colectiva y traumas políticos: investigación transcultural de los procesos sociales del recuerdo de sucesos políticos traumáticos. En D. Páez, J. Pennebaker, B. Rimé B, \& D. Jodelet, Memorias colectivas de procesos culturales y políticos. Bilbao: Servicio Editorial de la Universidad del País Vasco.

Páez, D., Márquez, J., \& Serra, A. (1998). Procesos de memoria colectiva asociados a experiencias traumáticas de guerra: reparto social, clima emocional ylatransmisión de la información transgeneracional en el caso de la guerra colonial portuguesa. En D. Páez, J. Pennebaker, B. Rimé, \& D. Jodelet, Memorias colectivas de procesos culturalesy políticos. Bilbao: Servicio Editorial de la Universidad del País Vasco.

Pakman, M. (1998). Psicoterapia en contextos de pobreza y disonancia étnica. En M. Pakman, Construcciones de la experiencia Humana (Vol. II). Buenos Aires: Gedisa. 
MUTUAL SUPPORT, AFFECTIVE LEADERSHIP, AND COMMUNITY REHABILITATION. AN EXPERIENCE OF PSYCHOSOCIALACCOMPANIMENT FOR THE "REHABILITATION" OFVICTIMSOF THE ARMEDCONFLICT.

Pakman, M. (2011). Palabras que permanecen, palabras por venir: micropolítica y poética en psicoterapia. Barcelona: Gedisa.

Pakman, M. (2014). Texturas de la imaginación, más allá de la ciencia empírica y el giro lingüístico. Barcelona: Gedisa.

Pennebaker, J. (1994). El arte de confiar en los demás. Madrid: Alianza Editorial.

Pennebaker, J. W., \& Crow, M. (2000). Memorias colectivas: la evolución y durabilidad de la historia. En A. Rosa Rivero, G. Belleli , \& D. Bakhurst, Memoria colectiva e identidad nacional (págs. 231 - 255). Madrid: Ensayo, Biblioteca Nueva.

Pillemer, D. B. (2003). Directive functions of autobiographical memory: The guiding power of the specific episode. Memory, 193 - 202.

Rogers, C. (1973). Grupos de encuentro. Buenos Aires: Amorrortu Editores.

UARIV. (2014). Elementos para la Incorporación del enfoque psicosocial en la atención, asistencia y reparación a las víctimas. Bogotá: UARIV, OIM, USAID.

Uprimny Yepes, R., \& Guzmán Rodríguez, D. E. (2010). En búsqueda de un concepto transformador y participativo para las reparaciones en contextos transicionales. Revista Colombiana de Derecho Internacional (17), 231-286.

Villa Gómez, J. D. (2012). La acción y el enfoque psicosocial de la intervención en contextos sociales. ¿Podemos pasar de la moda a la precisión teórica, epistemológica y metodológica?. El Ágora USB, 12(2), 349 - 365.

Villa Gómez, J. D. (2013). Horizontalidad, expresión y saberes compartidos: enfoque psicosocial en procesos de acompañamiento a víctimas de violencia política en Colombia. El Ágora USB, 13(2), 289 - 327.

Villa Gómez, J. D. (2013a). El Rol de la memoria en la recuperación emocional de las víctimas de violencia política en Colombia. International Journal of Psychological Research, 6(2), 37 - 49.

Villa Gómez, J. D. (2014). Recordar para reconstruir: El papel de la memoria colectiva en la reconstrucción del tejido social, el empoderamiento colectivo, la recuperación de la dignidad y la transformación subjetiva de las víctimas del conflicto armado en tres regiones de Colombia. Medellín: Editorial Bonaventuriana.

Villa Gómez, J. D. (2014b). Memoria, historias de vida y papel de la escucha en la transformación subjetiva de víctimas/ sobrevivientes del conflicto armado colombiano. El Ágora USB, 14(1), 37 - 60.

Villa Gómez, J. D. (2016). Intervenciones psicosociales en el marco de acciones de reparación a victimas del conflicto armado colombiano. ECA Estudios Centramericanos, 71(744), 81-104. Obtenido de http://www.uca.edu.sv/upload_w/20/file/744/5-\%20 Juan\%20David\%20Villa.pdf

Villa Gómez, J. D. (2016). Perdón y reconciliación: una perspectiva psicosocial desde la noviolencia. Revista Polis. 
Villa Gómez, J. D., \& González, P. A. (2012). Elementos para la Intervención Psicosocial y en Salud Mental a Víctimas de Violencia Política en Antioquia: Una propuesta para el personal psicosocial. Medellín, Colombia: Gobernación de Antioquia. Bicrear Diseño y Logística S.A.S.

Villa Gómez, J. D., Arroyave, L., Montoya, Y., \& Muñoz, A. (2015). Aspectos vocacionales y sentidos de vida en profesionales que trabajan en proyectos de atención psicosocial a víctimas de violencia política en Medellín y Antioquia. Revista de psicología UDEA, 7(2).

Villa Gómez, J. D., Arroyave, L., Montoya, Y., \& Muñoz, A. (2016). Vicisitudes de los proyectos institucionales de atención psicosocial a víctimas del conflicto armado colombiano. Revista Informes psicológicos, 16(2).

Villa Gómez, J. D., Londoño Díaz, D., \& Barrera Machado, D. (2014). Reparación a las víctimas de dictaduras, conflictos armados y violencia política en sus componentes de compensación, satisfacción, rehabilitación y no repetición. El Ágora USB, 14(2), $217-240$.

Villa Gómez, J., \& Insuasty Rodríguez, A. (2015). Significados en torno a la indemnización y la restitución en víctimas del conflicto armado en el municipio de San Carlos. El Ágora USB, 419-445.

Villa Gómez, J., \& Insuasty Rodríguez, A. (2016). Significados en torno a la indemnización y la restitución en víctimas del conflicto armado en el municipio de San Carlos. El Ágora USB, 165-191.

Villa Gómez, J., Tejada, C., Sánchez, N., \& Téllez, A. M. (2007). Nombrar lo Innombrable: Reconciliación desde la perspectiva de las Víctimas. Bogotá: Cinep. 